\title{
Research on Collision Response of Titanium Alloy Cylindrical Pressure Shell
}

\author{
Lin Wang, Xiang Jiang, Lei Huang \\ School of Ship and Ocean Engineering, Jiangsu University of Science and Technology, Zhenjiang, China \\ Email: 18852760372@163.com
}

How to cite this paper: Wang, L., Jiang, X. and Huang, L. (2020) Research on Collision Response of Titanium Alloy Cylindrical Pressure Shell. World Journal of Engineering and Technology, 8, 658-664.

https://doi.org/10.4236/wjet.2020.84046

Received: May 3, 2020

Accepted: October 28, 2020

Published: November 4, 2020

\begin{abstract}
Titanium alloy materials are widely used in the marine and aviation fields due to their excellent properties. The submersible sailing on the water surface is faster than underwater diving, so once an accident occurs, the consequences are unimaginable. Based on the failure criterion of the J-K model, this paper uses finite element simulation software to study the impact of impact velocity and impact angle on the collision response of a titanium alloy cylindrical pressure shell, providing a reference for the deep sea titanium alloy pressure shell.
\end{abstract}

\section{Keywords \\ Cylindrical Pressure Shell, Collision, Ferroalloy, Response}

\section{Introduction}

With the rapid development of today's world economy, the resources on land have fallen far short of human development needs, and countries all over the world have set their sights on the vast ocean. The ocean is one of the important spaces for human development. It is a strategic development base that integrates resources such as biological resources, energy, water resources, and metal resources. It is a great power for human exploration and protection of rights and interests. In 1950, scholars at home and abroad began to study the problem of ship collisions. One of the most important nodes or signs was the research paper published by the American scholar Minorsky "Journal of Ship Research" [1], which laid the foundation for the study of ship collisions. Since the 1960s, some foreign scholars or scientific research institutions have conducted numerous simulation experiments of ship collisions. For example, the German scholar Woisin [2] completed the collision test of a scale model of 12 ships according to the 
scale from 1:12 to 1:7.5. In order to study the impact resistance of different types of ships to the side, Vredeveldt, Wevers, etc. [3] completed 24 sets of model tests according to the model ratios of 1:15 and 1:10. Ito et al. [4] conducted an experimental study on the statics by using the inclined ship and the bulbous head to hit the double hull side structure of the ship.

In the late 1990s, shipyards and classification societies of Japan, Germany and the Netherlands commissioned the Netherlands Institute of Applied Physics [5] to conduct a total of 4 large-scale ship crash tests. The test data and results will be used to verify numerical analysis and test new structures of great significance.

Although, China has also carried out some research work on the ship-bridge collision problem in the early years, the ship-ship collision has been studied in the mid-1980s, and a small amount of research has been done on the theoretical analysis of ship collision Research, but due to the limitations of research technology and funding, there is still a certain gap with the international advanced level. Li Liangwei and Du Jianye [6] used the ship's scale model to analyze the impact of impact speed and impact angle on shipboard structure damage based on the collision test of the ship's towing tank and the simulation of the ship collision scheme in the marine environment.

Zhu Bangjun and Wan Zhengquan [7] proposed a calculation method for solving the stress of cylindrical compression shell from three angles of rib face plate, rib web and cylindrical shell, and analyzed the ribs by comparing specific examples with the specifications The influence of eccentricity on rib stress and shell plate stress is based on the standard method, combined with theory and model tests, and a suitable calculation method is derived.

Traditional submersibles use high-strength steel structures, but now they tend to use titanium alloy structures or composite materials to improve the submersible's carrying capacity and performance in all aspects. Titanium alloy has light weight, high specific strength, non-magnetic corrosion resistance and good heat resistance and low temperature resistance [8].

\section{Failure Criteria and Models}

\subsection{Failure Criteria}

In this paper, when using finite element software modeling, the model is used to define the dynamic properties of the titanium alloy material used in the cylindrical pressure shell. The general form is:

$$
\sigma=\left(A+B \varepsilon^{n}\right)\left[1+C\left(\frac{\dot{\varepsilon}}{\dot{\varepsilon}_{0}}\right)\right]\left[1-\left(T^{*}\right)^{m}\right]
$$

where: $\dot{\varepsilon}$-strain rate;

$\varepsilon$-Equivalent plastic strain;

$A, B, n, C, m$ - Material parameters.

The failure criterion adopted in Johnson-Cook model fully considers the development course of material damage. J-K model failure criterion judgment method: when the material failure parameter exceeds 1 , the material failure is as- 
sumed [9] [10]. The failure parameters are shown in Formula (2-2):

$$
\begin{gathered}
D=\sum \frac{\Delta \bar{\varepsilon}^{p}}{\varepsilon^{f}} \\
\varepsilon^{f}=\max \left(\left[D_{1}+D_{2} \exp D_{3} \sigma^{*}\right]\left[1+D_{4} \ln \dot{\varepsilon}^{*}\right]\left[1+D_{5} T^{*}\right], \text { EFMIN }\right)
\end{gathered}
$$

where: $\Delta \bar{\varepsilon}^{p}-$ Plastic strain increment at a time step;

$\varepsilon^{f}$-The stress state, strain and failure strain at temperature at the current time step;

EFMIN - The lower limit of strain at the time of failure;

$D_{1}-D_{5}-$ Material failure parameters.

\subsection{Finite Element Model}

Taking a certain type of submersible as the research object: its own weight is, with a ring-shaped rib, and the material used is TC4. Other structural parameters are shown in Table 1, and the model diagram is shown in Figure 1.

\section{Influencing Factors}

\subsection{Working Condition}

In order to study the impact of different impact velocities and impact angles on the collision response of cylindrical pressure shells, based on finite element software, the impact velocities and impact angles of $1 \mathrm{~m} / \mathrm{s}, 3 \mathrm{~m} / \mathrm{s}, 5 \mathrm{~m} / \mathrm{s}$ and 7 $\mathrm{m} / \mathrm{s}$ were selected as $90,60,45$. Typical operating conditions.

\subsection{Impact of Impact Speed}

As shown in Figures 2-4, the impact force, internal energy and kinetic energy of the cylindrical pressure shell vary with time under different impact speeds. It can be seen from the figure that when the impact velocity is $1 \mathrm{~m} / \mathrm{s}, 3 \mathrm{~m} / \mathrm{s}$, and $5 \mathrm{~m} / \mathrm{s}$, the duration of the peak collision force is all around $0.05 \mathrm{~s}$. When the impact
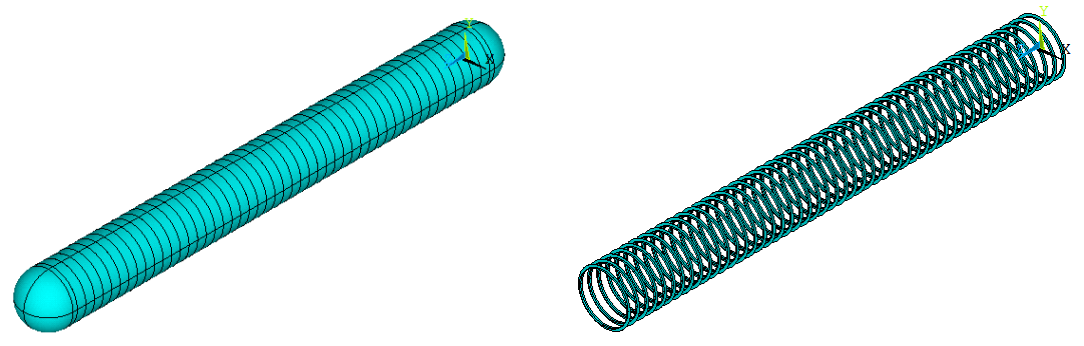

Figure 1. Finite element model of cylindrical pressure shell.

Table 1. The parameters of cylindrical pressure-resistant structure.

\begin{tabular}{cccccc}
\hline Parameter & Length L & Diameter D & Rib pitch l & Shell thickness t & Rib \\
\hline unit & $\mathrm{m}$ & $\mathrm{m}$ & $\mathrm{m}$ & $\mathrm{mm}$ & $\perp / \mathrm{mm}$ \\
\hline value & 21.6 & 2.3 & 0.4 & 33 & $\perp \frac{22 \times 160}{35 \times 100}$ \\
\hline
\end{tabular}


speed reaches $7 \mathrm{~m} / \mathrm{s}$, the peak of the collision force lasts very short, and the curve appears "jitter". This is due to the large impact speed, which causes the destruction of the pressure shell structure. The internal energy curve of the pressure structure can be verified. In terms of energy conversion, although the initial kinetic energy is different, the time until the end of the kinetic energy conversion is almost the same. Moreover, the initial kinetic energy is not completely converted into the internal energy of the pressure-resistant structure, and most of the energy is used for the destruction of the ship's side.

\subsection{Impact of Impact Angle}

As shown in Figures 5-7, the impact force and energy curves of cylindrical pressure shells at different impact angles. During the impact of the cylindrical pressure hull on the side of the ship, when the impact speed is the same and the

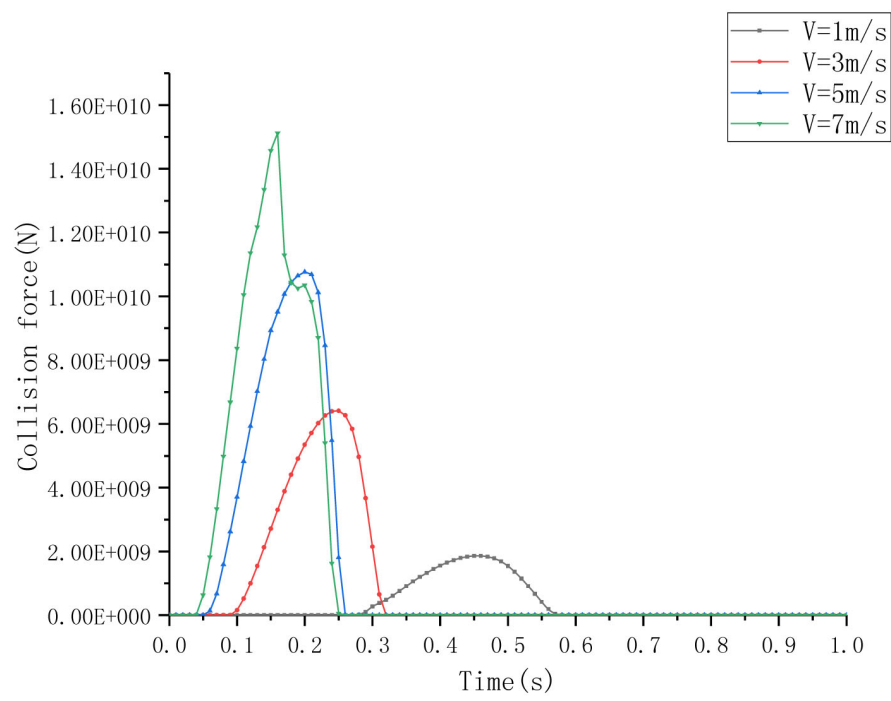

Figure 2. Stress diagram at different impact speeds.

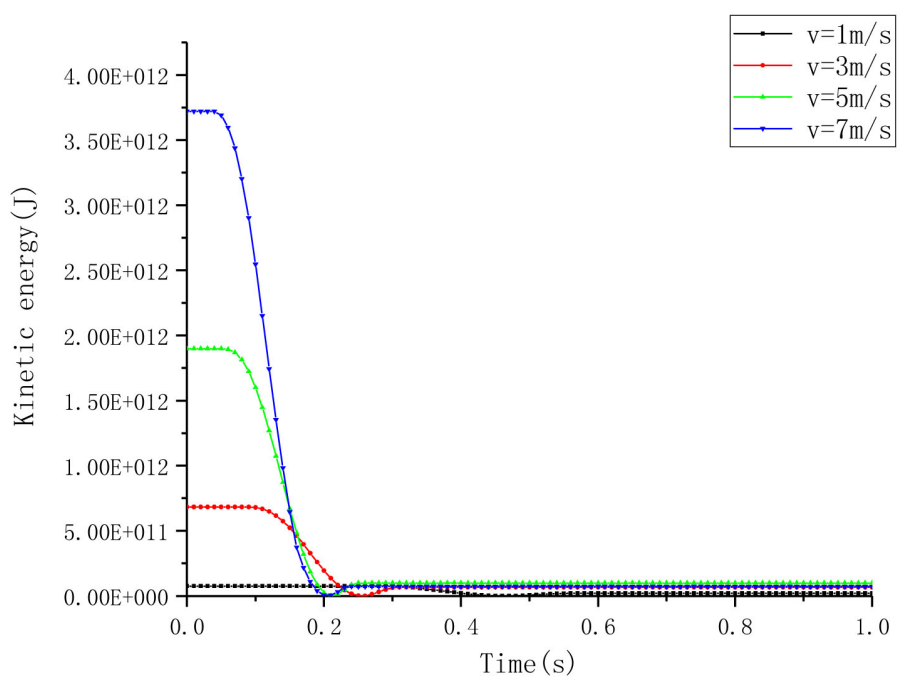

Figure 3. Kinetic energy curves at different impact velocities. 


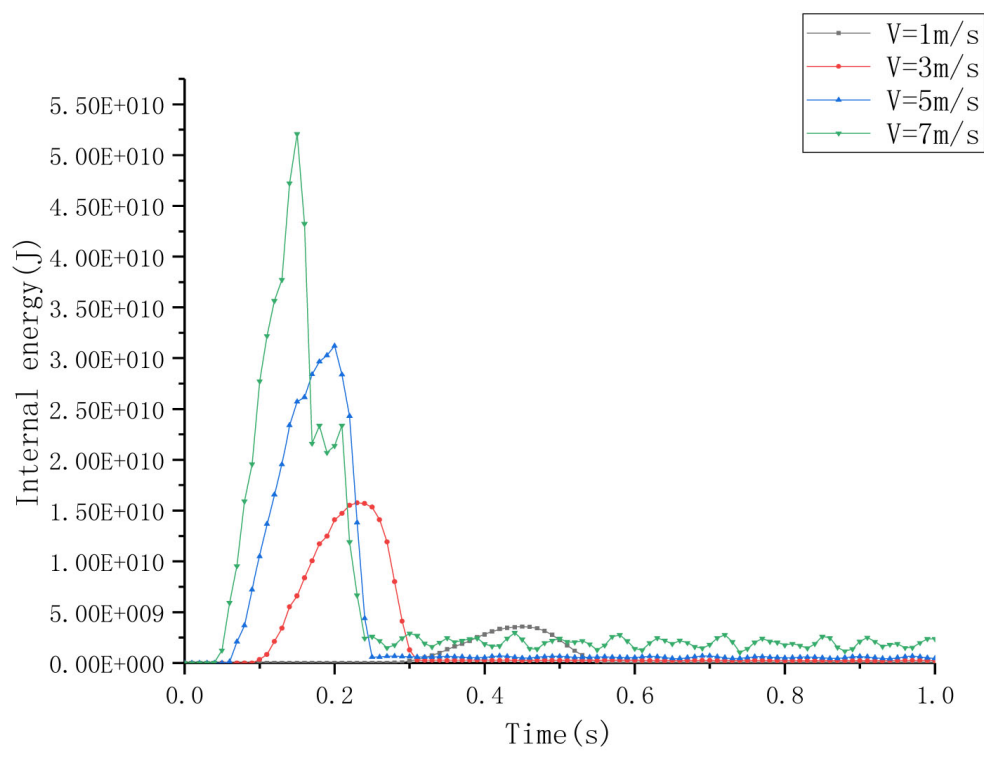

Figure 4. Internal energy curves at different impact velocities.

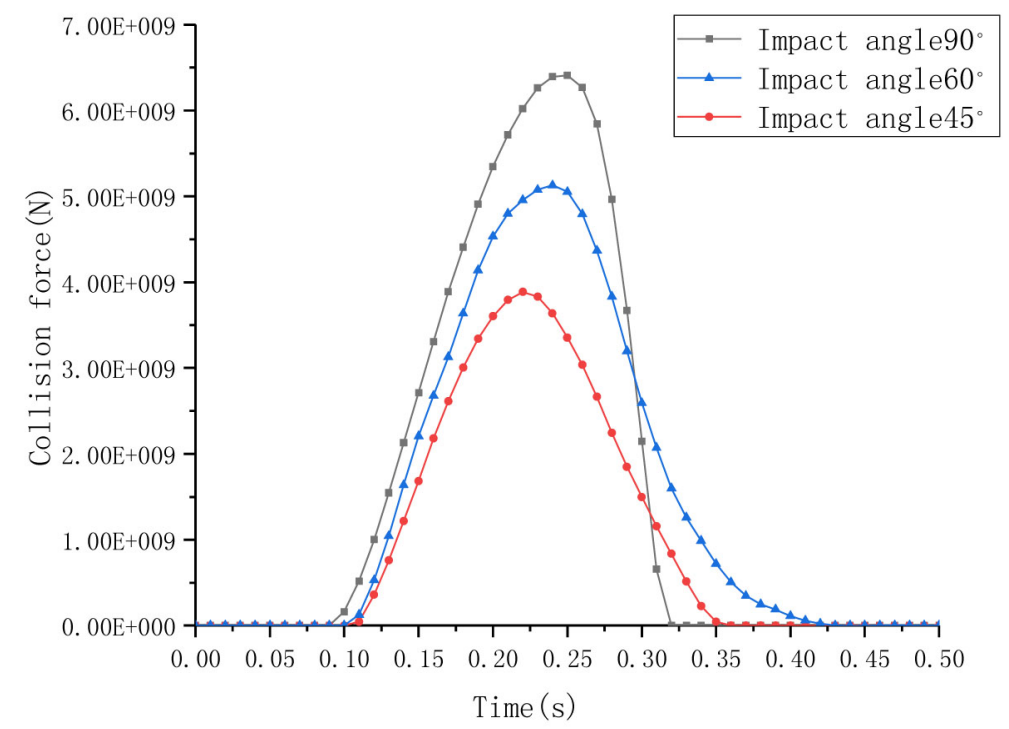

Figure 5. Collision force curve under different impact angles.

angle decreases, the duration of the collision force also increases, and the durations are $0.22 \mathrm{~s}, 0.24 \mathrm{~s}$ and $0.32 \mathrm{~s}$ respectively. In terms of energy, as the impact angle decreases, the kinetic energy conversion amount and conversion speed both decrease, and the internal energy peak of the housing also decreases. and. The peak of kinetic energy and internal energy are not in the same order of magnitude. This is because the initial kinetic energy is partly converted into shipboard energy.

\section{Conclusions}

This article fully analyzes the current status of ship collision research at home and abroad. On the basis of again, using finite element software and based on 


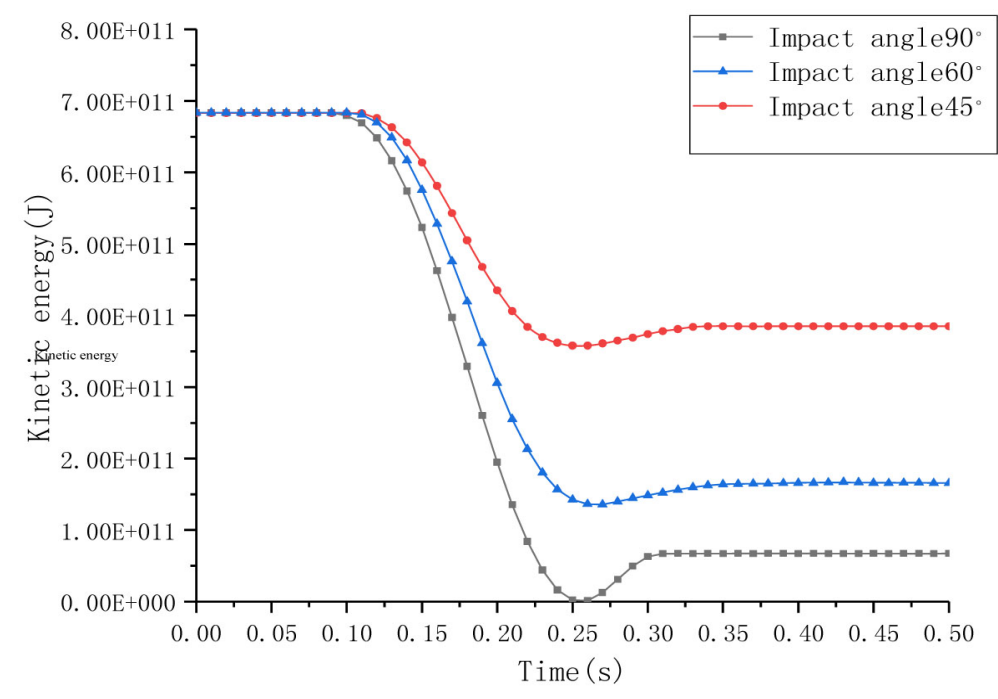

Figure 6. Kinetic energy curves at different impact angles.

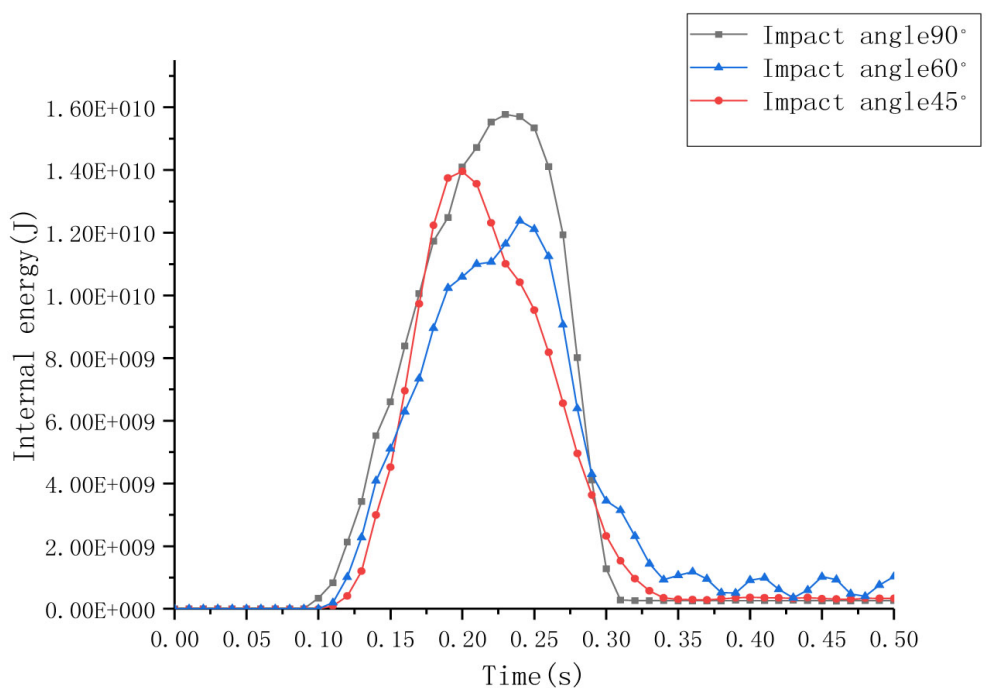

Figure 7. Internal energy curve under different impact angles.

the JK model failure criterion, the impact of impact speed and impact angle on the collision response of the titanium alloy cylindrical pressure shell is studied. in conclusion:

1) In general, the greater the impact speed and the greater the collision force, the more severe the damage to the cylindrical pressure shell and the faster the energy conversion;

2) When the other conditions are the same, the smaller the relative angle of impact, the longer the peak duration of the collision force, the energy conversion efficiency is reduced, and part of the energy is converted into the energy of the collision target due to friction.

\section{Conflicts of Interest}

The authors declare no conflicts of interest regarding the publication of this paper. 


\section{References}

[1] Minorsky, V.U. (1959) An Analysys of Ship Collision to Protection of Nuclear Powered Plant. J. Ship Research.

[2] Woisin, G. (1976) Collision Experiments of GKSS. Jahrbuch SYG, 70. Band.

[3] Vredeveldt, A.W. and Wevers, L.J. Full-Scale Ship Collision Test Results (Version 03). Building and Construction Research 892-0271. Delft, TNO Centre for Mechanical Engineering.

[4] Ito, H., Kondo, K., Yoshimura, N., et al. A Simplified Method to Analysis the Strength of Doublehulled Structures in Collision. 1st Report, J. of Naval Arch. Japan.

[5] Li, L.W. and Du, J.Y. (2018) Study on Collision Test of Ship Model Pool. Ship Science and Technology, 40, 64-67, 123.

[6] Broekhuijsen, L., Alsos, H.S., et al. (2008) Simulating the Collision Response of Ship Side Structures: A Failure Criteria Benchmark Study. International Shipbuilding Progress, 55, 127-144.

[7] Zhu, J.B. and Wan, Z.Q. (2004) A New Method for Stress Analysis of Ring-Ribbed Cylindrical Shells. Ship Mechanics, 8, 61-67.

[8] Wang, H.L. (2013) Application Status and Development of Titanium and Titanium Alloy in Marine Industry. Special Steel Technology, 4, 1-5.

[9] Liaw, D.G. and Yang, T.Y. (1991) Elastic-Plastic Dynamic Response and Buckling of Laminated Thin Shells. Journal of Composite Material, 25, 1039-1045. https://doi.org/10.1177/002199839102500805

[10] Ji, L.S. (2015) Research on the Ultimate Bearing Capacity of Deep Submersible Pressure Cylindrical Shell. Jiangsu University of Science and Technology. 